(2) Open Access Full Text Article

\title{
Investigation of alexithymia and levels of anxiety and depression among patients with restless legs syndrome
}

This article was published in the following Dove Press journal:

Neuropsychiatric Disease and Treatment

\section{Onur Yilmaz' \\ Yildizhan Șengül² \\ Hakan Serdar Șengül ${ }^{3}$ \\ Fatma Büșra Parlakkaya' \\ Ahmet Öztürk' \\ 'Bezmialem Foundation University Medical Faculty, Department of Psychiatry, Istanbul, Turkey; ${ }^{2}$ Bezmialem Foundation University Medical Faculty, Department of Neurology, Istanbul, Turkey; ${ }^{3}$ Gaziosmanpașa Taksim Research and \\ Training Hospital, Department of Psychiatry, Istanbul, Turkey}

Correspondence: Onur Yilmaz Bezmialem Foundation University Medical Faculty, Department of Psychiatry, Adnan Menderes Boulevard (Vatan Road), Fatih, Istanbul, 34093, Turkey

Tel +905336580934

Fax+90212 2531883

Email ony1978@gmail.com
Purpose: The purpose of this study was to examine alexithymia among restless legs syndrome (RLS) patients, compare with healthy controls, and argue the clinical inferences of this relationship. We searched for anxiety and depression and their clinical outcomes among patients and searched whether the results are similar to previous studies.

Patients and methods: Eighty-seven RLS patients and 88 age, gender, and educationally matched healthy controls were assessed in Bezmialem Foundation University Hospital. RLS patients and healthy controls were assessed with the Sociodemographic Data Form constructed for the present study, 20-item Toronto Alexithymia Scale (TAS-20), Beck Depression Inventory (BDI), and Beck Anxiety Scale (BAS). The patient group was also assessed with the International Restless Legs Syndrome Study Group (IRLSSG) RLS Severity Scale.

Results: RLS patients were found to have greater TAS-20, BDI, and BAS scores compared with the control group $(P<0.05)$. RLS severity score was positively correlated with the scores of anxiety and depression scales. However, no significant relationship was found between scores of IRLSSG RLS scale and TAS-20 total and subscale scores.

Conclusion: RLS patients were found to be more alexithymic than healthy controls, whereas no significant relationship was found between RLS severity and levels of alexithymia. Still, alexithymia might be a predictor for early diagnosis and may be considered in the treatment and follow-up of RLS. RLS patients have higher depression and anxiety scores than healthy individuals. Thus, depression and anxiety should be taken into consideration throughout the RLS treatment

Keywords: restless legs syndrome, alexithymia, anxiety, depression

\section{Plain language summary}

Restless legs syndrome (RLS) is a severely disturbing condition that makes daily life difficult for the patients. RLS patients may be diagnosed late, misdiagnosed, or even undiagnosed because the discomfort is usually described as crawling, pulling, drawing, tingling, prickling, and creeping. Recognizing and describing these symptoms is an abstruse issue to some extent. Interestingly, aching is seen in nearly $50 \%$ of RLS patients, which makes an early diagnosis even harder. Considering the severe disturbing conditions, the importance of early diagnosis is clear. Alexithymia is a situation in which the individual is to some extent unaware of his/ her feelings, experiences difficulty in describing them to other people, and lives daily life logically oriented. Alexithymic features are often significant from youth. Like RLS, alexithymic individuals are also under risk of depression and anxiety. RLS and alexithymia share certain neurobiologic characteristics. These associations drew our attention, and we intended to look for alexithymia among RLS patients, and as we expected, alexithymia was common. Since alexithymia is noticeable in youth and RLS diagnosis may be missed, we may consider to look 
for RLS among alexithymic individuals and raise our chance of an early diagnosis. Treatment of accompanying depression and anxiety will provide the patient a better quality of life.

\section{Introduction}

Restless legs syndrome (RLS) is classified under the title of "Sleep Related Movement Disorders" in the International Classification of Sleep Disorders, third edition (ICSD-3) produced by the American Academy of Sleep Medicine (updated in 2014). ${ }^{1}$ It is also known as a neurologic sensorimotor disorder. ${ }^{2}$ RLS is sometimes misdiagnosed or even unrecognized. Besides the discomforting conditions in the legs, which are the main symptoms, it can manifest frequently with insomnia, fatigue, pain, and depressive complaints. ${ }^{3,4}$ Although the pathophysiology of RLS is not fully understood, it has been reported that it may be related to impairments in dopamine metabolism. ${ }^{5,6}$

It is known that psychiatric disorders are common among RLS patients. It seems that there has been a recent increase in interest in this area. Studies have reported that depression and anxiety symptoms are more common in RLS patients than in healthy volunteers. ${ }^{7-10}$ RLS and depression may lead to the formation of each other, and one of the mechanisms thought to be involved in pathophysiology of both is the decrease in central dopaminergic activity. 5,6 There are growing numbers of studies reporting an association between RLS and anxiety symptoms. Chronic stress and depressive symptoms are associated with structural brain changes and impaired neuroplasticity. Some authors referred to specific neurobiological characteristics, which in turn lead to impaired neuroplasticity, for possible etiology of RLS. ${ }^{11}$ However, the number of studies investigating the relationship between the severity of RLS and the effect of RLS treatment on depression and anxiety symptoms is limited. ${ }^{8}$

The word alexithymia was suggested by Sifneos ${ }^{12}$ from the Greek ( $\mathrm{a}=$ lack, lexis = work, thymos = mood or emotion). Alexithymic individuals have difficulty in identifying their emotions, expressing them, and manifesting them by linking emotions and thoughts. ${ }^{12}$ The etiology of alexithymia is still controversial. ${ }^{13}$ To this end, studies focusing on childhood traumatic events and developmental and neurobiological factors continue. ${ }^{14,15}$ It has been suggested that alexithymic individuals have difficulty in discriminating between their emotions and their physical feelings resulting from physiological stimulation. ${ }^{16}$ For this reason, it might make sense that they are sensitive to psychosomatic diseases. Alexithymia is not a condition that is only seen in organic, psychiatric, or psychosomatic diseases. Alexithymic features may also be seen in general population. ${ }^{17,18}$ Various studies reported the prevalence of alexithymia (20-item Toronto Alexithymia Scale [TAS-20] total score, $\geq 61$ ) to be between $12 \%$ and $18 \%$. There has not been a consensus on gender difference for alexithymia. ${ }^{19,20}$ Low self-directedness (SD), low reward dependence (RD), and a minor degree harm avoidance (HA) were found to be independent predictors of alexithymia. ${ }^{21}$

In this trial, we aimed to investigate alexithymia and levels of depression and anxiety among RLS patients and compare them with healthy controls. To the best of our knowledge, a study investigating the relationship between RLS severity and alexithymia levels has not been performed previously. We also aimed to investigate this relationship in our study since the association of psychosomatic diseases as well as the deterioration of the dopaminergic response were suggested in both cases.

\section{Patients and methods}

This is a cross-sectional study performed at Department of Psychiatry and Department of Neurology of Bezmialem Foundation University. The study protocol was approved by Bezmialem Foundation University Ethics Committee for Non-Interventional Studies (approval date: October 2, 2017; approval number: 2017-10-04).

\section{Subjects}

Ninety-two patients diagnosed with RLS were selected for the study, 87 of whom completed the whole protocol. Two subjects from the patient group were excluded from the study because of accompanying conditions: one subject was found to be pregnant at the time of initial assessment and the other subject was diagnosed with chronic renal failure. Three subjects were not included in the study because they did not return after taking the tests. Education information of two subjects $(2.3 \%)$ and marital status of one subject $(1.1 \%)$ in the patient group were missing. One subject from the patient group (1.1\%) did not fill the TAS-20 completely, and we were unable to reach her. Consequently, 87 patients who were diagnosed with RLS according to the diagnostic criteria of the International Restless Legs Syndrome Study Group (IRLSSG) and 88 healthy controls who were matched for age, education, and gender were included in the study. Individuals aged 18 years or older were selected for the study. Patients with RLS symptoms who had comorbid conditions such as pregnancy, breastfeeding, renal failure, iron deficiency anemia, and endocrine disorders were not 
included in the study, to avoid secondary RLS. Patients who had been on antidepressant, anxiolytic, sedative, hypnotic and other psychiatric medication in the last two weeks before the evaluation date for the study were also not included because of the reciprocal effects of anxiety, depression, and RLS. While alcohol and tobacco usage were not conditions necessitating exclusion, individuals who developed either alcohol or tobacco dependency were not included.

The control group consisted of 88 individuals selected from healthy volunteers within the Bezmialem Foundation University employees and their family members. The authors and their family members were not included to avoid an unfavorable situation concerning ethics. After making necessary explanations about the study, subjects who accepted to participate have signed voluntary informed consent forms.

The Sociodemographic Data Form constructed for the study and Turkish versions of the TAS-20, the Beck Depression Inventory (BDI), and the Beck Anxiety Scale (BAS) were administered to both patient group and control subjects. Patient group also received the Turkish version of IRSSSG's RLS severity scale.

\section{IRLSSG RLS Severity Scale}

IRLSSG RLS Severity Scale, developed by IRLSSG, is a self-report scale consisting of 10 questions, in which typical and frequent symptoms of the syndrome are graded between 0 and 4 points according to the severity of the disease within the last week before the test date. A total score of $0-10$ is considered mild, 11-20 is moderate, $21-30$ is severe, and $31-40$ is very severe RLS. ${ }^{22}$

\section{TAS-20}

It is a Likert-type self-report scale. Each item is scored between 1 and 5. Some items are scored in reverse order. There are three subscales as follows: Difficulty in Identifying Feelings (TAS-1), Difficulty in Describing Feelings (TAS-2), and Externally Oriented Thinking (TAS-3). It is considered that the higher the total score, the more the alexithymic level. The scale was developed by Bagby et $\mathrm{al}^{23}$ and its Turkish adaptation was performed by Güleç et al. ${ }^{24}$ The TAS-20 total scores were categorized according to the cutoff points: a total score of $\geq 61$ points indicates alexithymia and $\leq 51$ points indicates no alexithymia.

\section{$\mathrm{BDI}$}

It is a self-report scale that evaluates emotional, cognitive, motivational, and somatic expressions frequently encountered in depression. It was developed by Aaron T. Beck. ${ }^{25}$ Each item measures the severity of a depression symptom, from mild to severe. While the least severity is graded with 0 point, the most severe condition of the symptom is rated with three points. It contains a total of 21 symptoms. The total score is between 0 and 63 . Turkish validity and reliability study was carried out by Hisli. ${ }^{26}$

\section{BAS}

It is a self-report scale based on the severity of anxiety symptoms. It was developed by Beck et al. ${ }^{27}$ It is a Likerttype scale consisting of 21 items, and each item is scored between 0 and 3 . Turkish validity and reliability study were performed by Ulusoy et al. ${ }^{28}$

\section{Data analysis}

Statistical evaluation of data was done with SPSS Statistics, version 24 (IBM Corporation, Armonk, NY, USA). All numerical variables were expressed as mean $\pm \mathrm{SD}$, while categorical variables were expressed with frequency and possibility tables.

Independent sample $t$-test (Student $t$-test) was used for comparison of numerical data, and chi-square test was used for comparison of categorical variables. Pearson correlation test was applied to investigate the correlation between numerical data. Partial correlation analysis was done to investigate the correlation between certain variables. $P$-value $<0.05$ was considered as statistically significant in all statistical analyses.

\section{Results}

Primary RLS is reported to be more common among women than men. ${ }^{2}$ Our sample was compatible with that, while the number of male patients $(\mathrm{n}=18,20.7 \%)$ was significantly lower than the number of female patients $(n=69,79.3 \%)$. Missing data insertion was not performed in SPSS because they were under $5 \%$, thus, not considered to be large enough to effect statistical analyses.

All of the selected 88 control subjects completed the study protocol.

There was no statistically significant difference between the mean age, education levels, and marital status of the patients and the control group. Profiles of alcohol drinking and tobacco smoking did not differ between the groups (Table 1).

The TAS-1, TAS-2, TAS-3, TAS-total, BDI, and BAS scores of the patients were compared with the scores of the control group (Table 2). 
Table I Comparison of sociodemographic data of patient and control group

\begin{tabular}{llll}
\hline Demographical data & $\begin{array}{l}\text { Patients } \\
(\mathbf{N}=\mathbf{8 7})\end{array}$ & $\begin{array}{l}\text { Controls } \\
(\mathbf{N}=\mathbf{8 8})\end{array}$ & P-value \\
\hline Age & $46.8 \pm 9.3$ & $44.4 \pm 10.8$ & $0.1 \mathrm{I}$ \\
$\begin{array}{l}\text { Gender } \\
\text { Female }\end{array}$ & $69(79.3 \%)$ & $67(76.1 \%)$ & $0.6 \mathrm{I}$ \\
Marital status & $66(76.8 \%)$ & $65(73.9 \%)$ & 0.70 \\
Married & $10(11.6 \%)$ & $14(15.9 \%)$ & \\
Single & $10(11.6 \%)$ & $9(10.2 \%)$ & \\
$\begin{array}{l}\text { Divorced, widow, separated } \\
\text { Alcohol }\end{array}$ & $21(24.1 \%)$ & $24(27.3 \%)$ & \\
Drinker & $37(42.5 \%)$ & $41(46.6 \%)$ & 0.63 \\
Tobacco & & & 0.664 \\
Smoker & $3(3.5 \%)$ & $3(3.4 \%)$ & \\
Education & $29(34.1 \%)$ & $28(31.8 \%)$ & \\
Literate & $29(36.5 \%)$ & $23(26.1 \%)$ & \\
Elementary & $13(15.3 \%)$ & $18(20.5 \%)$ & \\
High school & $11(10.6 \%)$ & $16(18.2 \%)$ & \\
$\begin{array}{l}\text { Associate licence, licence } \\
\text { Postgraduate, doctorate }\end{array}$ &
\end{tabular}

Notes: Independent sample $t$-test (Student's t-test) was used for comparison of numerical data, and chi-square test was used for comparison of categorical variables. Ages of both groups are expressed as mean \pm SD.

Abbreviations: $\mathrm{N}$, number of subjects; $P$, probability value.

The mean of the TAS total score and all subscale scores were significantly higher in the patient group than in the control group $(P<0.01)$.

Individuals who had a total TAS-20 score of $\geq 61$ are regarded as alexithymics. Thus, apart from comparison of TAS-20 scores, we compared patient and control groups with respect to the presence of alexithymia. Nineteen patients ( $22.1 \%$ of 86 patients, one patient did not fill in the TAS- 20

Table 2 Comparison of TAS-I, TAS-2, TAS-3, TAS-total, BDI, and BAS scores of patients and controls

\begin{tabular}{llll}
\hline Results & $\begin{array}{l}\text { Patients } \\
(\mathbf{N}=\mathbf{8 7})\end{array}$ & $\begin{array}{l}\text { Controls } \\
(\mathbf{N}=\mathbf{8 8})\end{array}$ & $\begin{array}{l}\text { P-value } \\
\end{array}$ \\
\hline TAS-I & $17.0 \pm 6.2$ & $10.3 \pm 2.4$ & $<0.0 \mathrm{I}$ \\
TAS-2 & $13.0 \pm 4.2$ & $10.2 \pm 3.3$ & $<0.0 \mathrm{I}$ \\
TAS-3 & $22.0 \pm 4.0$ & $16.3 \pm 4.1$ & $<0.0 \mathrm{I}$ \\
TAS-total & $51.8 \pm 10.6$ & $36.7 \pm 7.0$ & $<0.0 \mathrm{I}$ \\
Alexithymics (TAS-20 $\geq 6 \mathrm{I})$ & 19 & 7 & $<0.0 \mathrm{I}$ \\
BDI & $13.6 \pm 7.8$ & $7.4 \pm 5.2$ & $<0.01$ \\
Depressed (BDI $\geq 18)$ & 29 & 10 & $<0.01$ \\
BAS & $17.4 \pm 11.4$ & $9.0 \pm 7.1$ & $<0.01$ \\
\hline
\end{tabular}

Notes: Independent sample t-test (Student $t$-test) was used for comparison of numerical data. Scores of both groups are expressed as mean \pm SD. The presence of alexithymia and depression among two groups is compared with chi-square analysis.

Abbreviations: BAS, mean score of the Beck Anxiety Scale; BDI, mean score of the Beck Depression Inventory; N, number of subjects; $P$, probability value; TAS-20, 20-item Toronto Alexithymia Scale; TAS-I, mean score of the subscale Difficulty in Identifying Feelings; TAS-2, mean score of the subscale Difficulty in Describing Feelings; TAS-3, mean score of the subscale Externally Oriented Thinking; TAS-total, mean score of the TAS-20 total. form completely) and seven controls (7.9\% of 88 control samples) were found to be alexithymic. Chi-square test indicated a significant difference between groups $(P<0.01$; Table 2).

In comparison of the scores obtained from the BDI in two groups, the mean score of the scale was significantly higher in the patient group than in the control group $(P<0.01)$. Likewise, the mean score of the BAS was significantly higher in the patient group than in the control group $(P<0.01)$. The BDI has both an affective/cognitive and a somatic subscale. Considering RLS is a neuropsychiatric syndrome associated with psychosomatic symptoms, we also examined both subscale scores. Results were same as reported for total BDI $(P<0.01)$. Based on the information that a BDI score of $\geq 17$ indicates the presence of depression, we investigated the prevalence of depressed subjects among each group. Twenty-nine of 87 patients (33.3\%) and 10 of 88 controls $(11.4 \%)$ were determined to be depressive. Chi-square test indicated a significant difference between groups $(P<0.01$; Table 2).

We searched whether there was a relationship between RLS severity score and TAS-total, TAS-1, TAS-2, TAS-3, BDI, and BAS scores in the patient group (Table 3). No statistically significant relationship was found between the RLS severity score and TAS-1, TAS-2, TAS-3, and TAS total scores of patients. Positive correlations were found between RLS severity score and BDI and BAS scores $(P<0.01$ for BDI and $P<0.043$ for BAS). As it is seen, the positive correlation between the RLS severity score and the BDI score is more significant than the positive correlation between RLS and BAS scores.

Other notable findings are that BDI and BAS scores were positively correlated with TAS-1, TAS-2, and TAS-total scores, while no statistically significant relationship was found with TAS-3 scores. Besides, TAS- 1 and TAS-3 scores were also not found to be correlated significantly.

\section{Discussion}

The main result of the current study was that alexithymia scores in RLS patients were higher than healthy volunteers. Similar to previous studies, anxiety and depression scores of patients were also shown to be higher.

It is known that psychiatric disorders are common among RLS patients. The first study to mention the comorbidity of psychiatric disorders in these patients was published in 1965. In this study, depression scores of RLS patients were found to be higher than that of the general population. ${ }^{29}$ In a study evaluating the elderly patient population, it was 
Table 3 Correlations of RLS, TAS-I, TAS-2, TAS-3, TAS-total, BDI and BAS scores through patient group

\begin{tabular}{|c|c|c|c|c|c|c|c|}
\hline & RLS & TAS-I & TAS-2 & TAS-3 & TAS-total & BDI & BAS \\
\hline RLS & & 0.141 & 0.510 & 0.154 & 0.062 & $<0.01$ & 0.043 \\
\hline TAS-I & 0.141 & & $<0.01$ & 0.301 & $<0.01$ & $<0.01$ & $<0.01$ \\
\hline TAS-2 & 0.510 & $<0.01$ & & 0.03 & $<0.01$ & $<0.01$ & 0.012 \\
\hline TAS-3 & 0.154 & 0.301 & 0.03 & & $<0.01$ & 0.416 & 0.190 \\
\hline TAS-total & 0.062 & $<0.01$ & $<0.01$ & $<0.01$ & & $<0.01$ & $<0.01$ \\
\hline $\mathrm{BDI}$ & $<0.01$ & $<0.01$ & $<0.01$ & 0.416 & $<0.01$ & & $<0.01$ \\
\hline BAS & 0.043 & $<0.01$ & 0.012 & 0.190 & $<0.01$ & $<0.01$ & \\
\hline
\end{tabular}

Notes: Significant correlations are indicated in bold. Pearson correlation analysis was performed.

Abbreviations: BAS, mean score of the Beck Anxiety Scale; BDI, mean score of the Beck Depression Inventory; RLS, mean score of International Restless Legs Syndrome Study Group RLS Severity Scale; TAS-I, mean score of the subscale Difficulty in Identifying Feelings; TAS-2, mean score of the subscale Difficulty in Describing Feelings; TAS-3, mean score of the subscale Externally Oriented Thinking; TAS-total, mean score of the TAS-20 total.

found that the incidence of depression was higher for those with RLS, and mental health scores calculated with the 36-item short form were lower. ${ }^{30}$ One study reported that RLS patients had higher depression and anxiety scores than healthy controls and that electroencephalography changes were similar to patients who have major depression. ${ }^{31}$ Apart from the dopaminergic mechanism in the etiology of RLS, glutamatergic, serotonergic, and opioid neurotransmitter mechanisms were also argued to be impaired. ${ }^{32-34}$ The association among impaired neurogenesis, neurotrophic factors, and stress-related conditions are of particular interest. In a trial regarding this, the authors argued specific neurobiological characteristics such as glutamatergic, serotonergic, and opioid neurotransmitter impairments, which in turn may be associated with impairments of neuroplasticity mechanisms, as a possible etiology of RLS. ${ }^{35}$ Sympathetic overactivity is also associated with RLS as manifested by increased pulse rate and blood pressure. ${ }^{36}$ Also, notable relationships were reported among RLS, hypertension (HT), heart diseases, and stroke. ${ }^{37}$ Thirty-nine patients $(44.8 \%)$ were diagnosed with HT, while 14 (16.1\%) had cardiac diseases. Both groups were on regular medication. The odds ratio (OR) for the association of HT with RLS was 1.29 (95\% CI, 1.12-1.64; $P<0.001)$ and for the association of heart disease with RLS was 1.45 (95\% CI, 1.09-1.93; $P<0.05$ ).

The number of studies investigating the relationship between RLS and anxiety disorders has also increased in recent years. In one study, RLS was shown to be associated with major depressive disorder and panic disorder. ${ }^{38}$ In another study, psychiatric disorders such as major depressive disorder, panic disorder, and posttraumatic stress disorder, diagnosed according to the Diagnostic and Statistical Manual of Mental Disorders-IV (DSM-IV) criteria, were found to be associated with RLS. ${ }^{39}$ In the study performed by Sevim et al, ${ }^{8}$ it was found that the severity of RLS is directly related to depression and anxiety scores. Severely affected RLS patients were reported to show psychological impairment in multiple psychological domains, which has to be taken into account in the treatment regimen. Serious side effects of the dopaminergic first-line treatment were proclaimed to be accompanied with the highest psychological distress, as seen particularly in the normative values of the compulsivity and anxiety subscales of Symptom Checklist-90-Revised. ${ }^{40}$

One of the most important findings of our work is increased alexithymia scores among patients. To the best of our knowledge, no previous study was carried out on alexithymic characteristics in RLS patients. It is suggested that the right prefrontal cortex is the cortical center of unconscious because of its role in nonverbal communication, stress management, and mood regulation. ${ }^{41}$ According to some researchers, in individuals with traumatic events in early life, the development of the right prefrontal cortex may be suppressed in order to maintain a state of mental equilibrium, which may lead to impaired mood regulation. This may cause increased sympathetic activity and impaired dopaminergic and glutamatergic systems. ${ }^{42}$ Postmortem studies have demonstrated dopaminergic projections in both the anterior cingulate cortex (ACC) and the anterior insular cortex (AIC; both are located in the prefrontal cortex) and the presence of dopamine type- 2 receptors (D2 receptors) in both regions. ${ }^{43,44}$ The association of alexithymia and dopaminergic dysfunction may be more pronounced when taken together with studies that show a high level of alexithymia in neurological disorders associated with dopaminergic dysfunction such as Parkinson's disease. ${ }^{45}$ In a study investigating alexithymia measured by TAS-20, D2 receptor binding potency of ACC and AIC in healthy volunteers was reported to be positively correlated with the TAS-20 total score. ${ }^{46}$ The relationship between RLS and impairment of dopaminergic neurotransmitter system have been mentioned above. ${ }^{3,4}$ Long-term treatment of RLS with dopamine D2/D3 receptor agonists is reported to lead to augmentation; moreover, alterations in 
direct and indirect interactions between D1 and D3 receptors were argued to be involved. ${ }^{47}$ Dorsolateral prefrontal cortex (DLPFC), basal ganglia, and associated dopaminergic networks were assessed among RLS patients. Late-onset RLS is reported to be associated with low iron content of the basal ganglia and increased activity of the DLPFC. ${ }^{48}$ Early-onset RLS is associated with increased iron content of the globus pallidus internal and substantia nigra, suggesting dysfunction of the basal ganglia. Activation of the striatofrontolimbic area may represent the neurofunctional substrate mediating the repetitive compulsive movements seen in RLS. ${ }^{49}$

Psychosomatic symptoms often go along with RLS. ${ }^{50}$ Alexithymic patients are also susceptible to psychosomatic disorders. Hence, the relationship between alexithymia and various psychosomatic diseases has recently became noticeable. In a study comparing irritable bowel syndrome (IBS) patients with healthy volunteers, IBS patients were more likely to have alexithymia. ${ }^{51}$ In another study, it was reported that there is an association between alopecia areata and alexithymia. ${ }^{52}$ A study comparing psoriasis patients with patients suffering from skin diseases with no psychosomatic background revealed that alexithymic features were more common in psoriasis patients. ${ }^{53}$

On the basis of these previous and our current findings, we may suggest that greater scores of alexithymia among RLS patients in our study is presumably due to concomitant impaired dopaminergic function, frequent association with psychosomatic disorders, and frequent association with depression and anxiety in both situations.

The current study also aimed to examine the relationship between RLS severity and alexithymia scores among patients. In this respect, as far as we know, it is the first study in that field. There are studies reporting that cortical D2 receptor density is decreasing as age progresses. ${ }^{54}$ Partial correlation analysis we carried out in our study revealed that alexithymia and RLS association was not affected by age. Certain studies reported that the density of cortical D2 receptors varies according to gender. ${ }^{55}$ Although the number of male patients in our study was significantly lower than the number of female patients, we found that the relationship between alexithymia and RLS was not affected by age.

There was a positive correlation between the severity of RLS and depression and anxiety scores in the patients, but no significant correlation was found between RLS severity and alexithymia scores. We could not explain this finding directly. Even so, we can speculate that this finding is because of the excess number of factors affecting the severity of RLS and the role of other neurotransmitters except dopamine. Impairment of dopaminergic activity is the main pathogenesis involved in primary RLS. However, dopaminergic impairment is not accepted to be the main pathogenesis in alexithymia. Most importantly, alexithymia is generally accepted to be a personality trait rather than a disorder. Thus, we may speculate that alexithymic individuals have more tendency to get anxiety, depression, and probably RLS, although treatment or severity of RLS might have only a mild effect on scores of alexithymia. ${ }^{56}$

There are some limitations of the study. One is that we did not get information about the menopausal status of female patients. After the study was completed, we also failed to reach the correct data regarding menopausal status of most of our female subjects. However, researchers reported elevated symptomatology of RLS during menopause. ${ }^{57,58}$ We did not measure dopamine levels biochemically, which might be considered as a limitation since we argued that impairment of dopamine metabolism was common among both RLS and alexithymia. A further limitation is that, while the total score of the TAS-20 and the first two subscale scores had a positive correlation with the BDI and the BAS scores, there was no positive correlation with the Externally Oriented Thinking (TAS-3) subscale scores, a finding that we cannot explain clearly. Also it was an unexpected finding that there was no significant relationship between TAS-3 and TAS-1 scores. Some recent studies already reported conflicting results about TAS-3 subscale to the extent that alexithymia can be reliably assessed in adolescents using the TAS-20 without some items rating the Externally Oriented Thinking (TAS-3) dimension. ${ }^{59,60}$ This information may indicate that there is a need for further studies to examine TAS-3 subscale in more detail.

\section{Conclusion}

We suggest that, alexithymia might be a predictor for early diagnosis of RLS. It may be considered in treatment and follow-up of RLS and maybe other neuropsychiatric and psychosomatic disorders. Thus, it might be necessary to investigate the relationship between RLS and alexithymia in further advanced studies, preferably in the light of neuroimaging methods, and neurobiological mechanisms concerning neurotransmitters and the concept of neuroplasticity. Depression and anxiety symptoms should also be taken into consideration throughout RLS treatment and follow-up period.

\section{Acknowledgments}

Professor İsmet Kirpınar, MD, Bezmialem Foundation University Medical Faculty, Head of the Department of 
Psychiatry, Istanbul, Turkey, provided advice and shared their experience. Resident Tezer Kılıçarslan, MD, Bezmialem Foundation University Medical Faculty, Department of Psychiatry, Istanbul, Turkey, conducted TAS-20, BDI, and BAS for some of the control subjects.

\section{Author contributions}

All authors contributed toward data analysis, drafting and critically revising the paper, gave final approval of the version to be published, and agree to be accountable for all aspects of the work.

\section{Disclosure}

The authors report no conflicts of interest in this work.

\section{References}

1. Thorpy M. International classification of sleep disorders. In: Chokroverty S, editor. Sleep Disorders Medicine. New York, NY: Springer; 2017:475-484

2. Perrier L, Emery MP, Anfray C, Acquadro C. Importance of clinical outcome assessment (COA) data in the evaluation of medicines for the treatment of restless legs syndrome (RLS). Proceedings of the 3rd Congress of the European Academy of Neurology. Amsterdam, the Netherlands, June 24-27, 2017. New York: Elsevier Science INC; 2017.

3. Earley CJ, Restless legs Syndrome. N Engl J Med. 2003;348(21): 2103-2109.

4. Allen RP, Picchietti D, Hening WA, et al. Restless legs syndrome: diagnostic criteria, special considerations, and epidemiology. A report from the restless legs syndrome diagnosis and epidemiology workshop at the National Institutes of Health. Sleep Med. 2003;4(2):101-119.

5. Montplaisir J, Lorrain D, Godbout R. Restless legs syndrome and periodic leg movements in sleep: the primary role of dopaminergic mechanism. Eur Neurol. 1991;31(1):41-43.

6. Picchietti D, Winkelman JW. Restless legs syndrome, periodic limb movements in sleep, and depression. Sleep . 2005;28(7):891-898.

7. Trenkwalder C, Paulus W, Walters AS. The restless legs syndrome. Lancet Neurol. 2005;4(8):465-475.

8. Sevim S, Dogu O, Kaleagasi H, Aral M, Metin O, Camdeviren H. Correlation of anxiety and depression symptoms in patients with restless legs syndrome: a population based survey. $J$ Neurol Neurosurg Psychiatry. 2004;75(2):226-230.

9. Cho CH, Kim L, Lee HJ. Individuals with Restless Legs Syndrome Tend to have Severe Depressive Symptoms: Findings from a CommunityBased Cohort Study. Psychiatry Investig. 2017;14(6):887-893.

10. Hornyak M. Depressive Disorders in Restless Legs Syndrome. CNS Drugs. 2010;24(2):89-98.

11. Radley J, Morilak D, Viau V, Campeau S. Chronic stress and brain plasticity: Mechanisms underlying adaptive and maladaptive changes and implications for stress-related CNS disorders. Neurosci Biobehav Rev. 2015;58:79-91.

12. Sifneos PE. The prevalence of alexithymic characteristics in psychosomatic patients. Psychother Psychosom. 1973;22(2):255-262.

13. Pellerone M, Cascio MI, Costanzo G, Gori A, Pace U, Craparo G. Alexithymia and psychological symptomatology: research conducted on a non-clinical group of Italian adolescents. Int J Cult Mental Health. 2017; 10(3):300-309.

14. Bermond B, Moormann PP, Albach F, van Dijke A. Impact of severe childhood sexual abuse on the development of alexithymia in adulthood. Psychother Psychosom. 2008;77(4):260-262.

15. Karukivi M, Saarijärvi S. Development of alexithymic personality features. World J Psychiatry. 2014;4(4):91.
16. Meza-Concha N, Arancibia M, Salas F, et al. Towards a neurobiological understanding of alexithymia. Medwave. 2017;17(4):6960.

17. Sasioglu M, Gulol C, Tosun A. The Concept of Alexithymia. Current Approaches in Psychiatry. 2013;5(4):507.

18. Joukamaa M, Taanila A, Miettunen J, Karvonen JT, Koskinen M, Veijola J. Epidemiology of alexithymia among adolescents. J Psychosom Res. 2007;63(4):373-376.

19. Salminen JK, Saarijärvi S, Aärelä E, Toikka T, Kauhanen J. Prevalence of alexithymia and its association with sociodemographic variables in the general population of Finland. J Psychosom Res. 1999;46(1):75-82.

20. Mason O, Tyson M, Jones C, Potts S. Alexithymia: Its prevalence and correlates in a British undergraduate sample. Psychol Psychother. 2005; 78(1):113-125.

21. Grabe HJ, Spitzer C, Freyberger HJ. Alexithymia and the temperament and character model of personality. Psychother Psychosom. 2001; 70(5):261-267.

22. Walters AS, Lebrocq C, Dhar A, et al. Validation of the International Restless Legs Syndrome Study Group rating scale for restless legs syndrome. Sleep Med. 2003;4(2):121-132.

23. Bagby RM, Parker JD, Taylor GJ. The twenty-item Toronto Alexithymia Scale - I. Item selection and cross-validation of the factor structure. J Psychosom Res. 1994;38(1):23-32.

24. Güleç H, Köse S, Güleç MY. Reliability and factorial validity of the Turkish version of the 20-item Toronto alexithymia scale (TAS-20). Klinik Psikofarmakol Bülteni. 2009;19(3):214-220.

25. Beck AT, Ward CH, Mendelson M, Mock J, Erbaugh J. An inventory for measuring depression. Arch Gen Psychiatry. 1961;4:561-571.

26. Hisli N. Beck Depresyon Ölçeğinin bir Türk örnekleminde geçerlilik ve güvenilirliği [Reliability and validity of Beck Depression Scale in a Turkish sample]. Psikoloji Dergisi. 1988;6:118-122. Turkish.

27. Beck AT, Epstein N, Brown G, Steer RA. An inventory for measuring clinical anxiety: psychometric properties. J Consult Clin Psychol. 1988;56(6):893-897.

28. Ulusoy M, Sahin NH, Erkmen H. Turkish version of the Beck Anxiety Inventory: psychometric properties. J Cogn Psychother. 1998; 12(2): 163

29. Gorman CA, Dyck PJ, Pearson JS. Symptom of restless legs. Arch Intern Med. 1965;115:155-160.

30. Rothdach AJ, Trenkwalder C, Haberstock J, Keil U, Berger K. Prevalence and risk factors of RLS in an elderly population: The MEMO Study. Neurology. 2000;54(5):1064-1068.

31. Saletu M, Anderer P, Saletu B, Lindeck-Pozza L, Hauer C, SaletuZyhlarz G. EEG mapping in patients with restless legs syndrome as compared with normal controls. Psychiatry Res. 2002;115(1-2):49-61.

32. Allen RP, Barker PB, Horská A, Earley CJ. Thalamic glutamate/ glutamine in restless legs syndrome: increased and related to disturbed sleep. Neurology. 2013;80(22):2028-2034.

33. Jhoo JH, Yoon IY, Kim YK, et al. Availability of brain serotonin transporters in patients with restless legs syndrome. Neurology. 2010;74(6): 513-518.

34. Walters AS, Ondo WG, Zhu W, Le W. Does the endogenous opiate system play a role in the Restless Legs Syndrome? A pilot post-mortem study. J Neurol Sci. 2009;279(1-2):62-65.

35. Serafini G, Hayley S, Pompili M, et al. Hippocampal neurogenesis, neurotrophic factors and depression: possible therapeutic targets? CNS Neurol Disord Drug Targets. 2014;13(10):1708-1721.

36. Ulfberg J, Nyström B, Carter N, Edling C. Prevalence of restless legs syndrome among men aged 18 to 64 years: an association with somatic disease and neuropsychiatric symptoms. Mov Disord. 2001;16(6): 1159-1163.

37. Walters AS, Rye DB. Review of the relationship of restless legs syndrome and periodic limb movements in sleep to hypertension, heart disease, and stroke. Sleep. 2009;32(5):589-597.

38. Lee HB, Hening WA, Allen RP, et al. Restless legs syndrome is associated with DSM-IV major depressive disorder and panic disorder in the community. J Neuropsychiatry Clin Neurosci. 2008; 20(1):101-105. 
39. Cho SJ, Hong JP, Hahm BJ, et al. Restless legs syndrome in a community sample of Korean adults: prevalence, impact on quality of life, and association with DSM-IV psychiatric disorders. Sleep. 2009;32(8): 1069-1076.

40. Scholz H, Benes H, Happe S, Bengel J, Kohnen R, Hornyak M. Psychological distress of patients suffering from restless legs syndrome: a cross-sectional study. Health Qual Life Outcomes. 2011;9(1):73.

41. Gainotti G. Unconscious processing of emotions and the right hemisphere. Neuropsychologia. 2012;50(2):205-218.

42. Schore AN. Relational trauma, brain development and dissociation. In: Ford JD, Courtois CA, editors. Treating Complex Traumatic Stress Disorders in Children and Adolescents: Scientific Foundations and Therapeutic Models. New York: The Guilford Press; 2013:3-23.

43. Gaspar P, Berger B, Febvret A, Vigny A, Henry JP. Catecholamine innervation of the human cerebral cortex as revealed by comparative immunohistochemistry of tyrosine hydroxylase and dopamine-betahydroxylase. J Comp Neurol. 1989;279(2):249-271.

44. Hall H, Farde L, Halldin C, Hurd YL, Pauli S, Sedvall G. Autoradiographic localization of extrastriatal D2-dopamine receptors in the human brain using [125I] epidepride. Synapse. 1996;23(2):115-123.

45. Costa A, Peppe A, Carlesimo GA, Salamone G, Caltagirone C. Prevalence and characteristics of alexithymia in Parkinson's disease. Psychosomatics. 2010;51(1):22-28.

46. Okita K, Ghahremani DG, Payer DE, Robertson CL, Mandelkern MA, London ED. Relationship of Alexithymia Ratings to Dopamine D2-type Receptors in Anterior Cingulate and Insula of Healthy Control Subjects but Not Methamphetamine-Dependent Individuals. Int J Neuropsychopharmacol. 2016;19(5):pyv129.

47. Earley CJ, Uhl GR, Clemens S, Ferré S. Connectome and molecular pharmacological differences in the dopaminergic system in restless legs syndrome (RLS): plastic changes and neuroadaptations that may contribute to augmentation. Sleep Med. 2017;31:71-77.

48. Astrakas LG, Konitsiotis S, Margariti P, Tsouli S, Tzarouhi L, Argyropoulou MI. T2 relaxometry and fMRI of the brain in late-onset restless legs syndrome. Neurology. 2008;71(12):911-916.

49. Margariti PN, Astrakas LG, Tsouli SG, Hadjigeorgiou GM, Konitsiotis S, Argyropoulou MI. Investigation of unmedicated early onset restless legs syndrome by voxel-based morphometry, T2 relaxometry, and functional MR imaging during the night-time hours. AJNR Am J Neuroradiol. 2012;33(4):667-672.
50. Kim JB, Koo YS, Eun MY, Park KW, Jung KY. Psychosomatic symptom profiles in patients with restless legs syndrome. Sleep Breath. 2013; 17(3):1055-1061.

51. Portincasa P, Moschetta A, Baldassarre G, Altomare DF, Palasciano G. Pan-enteric dysmotility, impaired quality of life and alexithymia in a large group of patients meeting ROME II criteria for irritable bowel syndrome. World J Gastroenterol. 2003;9(10):2293.

52. Cordan Yazici A, Başterzi A, Tot Acar S, et al. Alopecia areata and alexithymia. Turk Psikiyatri Derg. 2006;17(2):101-106.

53. Picardi A, Mazzotti E, Gaetano P, et al. Stress, social support, emotional regulation, and exacerbation of diffuse plaque psoriasis. Psychosomatics. 2005;46(6):556-564.

54. Kaasinen V, Vilkman H, Hietala J, et al. Age-related dopamine D2/D3 receptor loss in extrastriatal regions of the human brain. Neurobiol Aging. 2000;21(5):683-688.

55. Kaasinen V, Någren K, Hietala J, Farde L, Rinne JO. Sex differences in extrastriatal dopamine d(2)-like receptors in the human brain. Am J Psychiatry. 2001;158(2):308-311.

56. Taylor GJ, Bagby RM. The alexithymia personality dimension. In: Widiger TA, editor. Oxford Library of Psychology. The Oxford Handbook of Personality Disorders. New York, NY, US: Oxford University Press; 2012:648-673.

57. Ghorayeb I, Bioulac B, Scribans C, Tison F. Perceived severity of restless legs syndrome across the female life cycle. Sleep Med. 2008;9(7): 799-802.

58. Wesström J, Nilsson S, Sundström-Poromaa I, Ulfberg J. Restless legs syndrome among women: prevalence, co-morbidity and possible relationship to menopause. Climacteric. 2008;11(5):422-428.

59. Li S, Zhang B, Guo Y, Zhang J. The association between alexithymia as assessed by the 20-item Toronto Alexithymia Scale and depression: A meta-analysis. Psychiatry Res. 2015;227(1):1-9.

60. Craparo G, Faraci P, Gori A. Psychometric Properties of the 20-Item Toronto Alexithymia Scale in a Group of Italian Younger Adolescents. Psychiatry Investig. 2015;12(4):500.
Neuropsychiatric Disease and Treatment

\section{Publish your work in this journal}

Neuropsychiatric Disease and Treatment is an international, peerreviewed journal of clinical therapeutics and pharmacology focusing on concise rapid reporting of clinical or pre-clinical studies on a range of neuropsychiatric and neurological disorders. This journal is indexed on PubMed Central, the 'PsycINFO' database and CAS,

\section{Dovepress}

and is the official journal of The International Neuropsychiatric Association (INA). The manuscript management system is completely online and includes a very quick and fair peer-review system, which is all easy to use. Visit http://www.dovepress.com/testimonials.php to read real quotes from published authors. 